\title{
Energy dispersive X-ray fluorescence spectroscopy/Monte Carlo simulation approach for the non-destructive analysis of corrosion patina-bearing alloys in archaeological bronzes: The case of the bowl from the Fareleira 3 site (Vidigueira, South Portugal)
}

\author{
C. Bottaini ${ }^{\text {a }}$, J. Mirão ${ }^{\mathrm{a}, \mathrm{b}}$, M. Figuereido ${ }^{\mathrm{c}}$, A. Candeias ${ }^{\mathrm{a}, \mathrm{d}}$, A. Brunetti ${ }^{\mathrm{e}}$, N. Schiavon ${ }^{\mathrm{a}, \mathrm{b}, *}$ \\ a Hercules Laboratory, University of Évora, Palacio do Vimioso, Largo Marquês de Marialva 8, 7000-809 Évora, Portugal \\ b Évora Geophysics Centre, Rua Romão Ramalho 59, 7000 Évora, Portugal \\ c Archaeologist - Monte da Capelinha, Apartado 54, 7005, São Miguel de Machede, Évora, Portugal \\ d Évora Chemistry Centre, Rua Romão Ramalho 59, 7000 Évora, Portugal \\ e Department of Political Science and Communication, University of Sassari, Via Piandanna 2, 07100 Sassari, Italy
}

\section{A R T I C L E I N F O}

\section{Article history:}

Received 18 June 2014

Accepted 31 October 2014

Available online 9 November 2014

\section{Keywords:}

Monte Carlo simulation

EDXRF

$\mu X R D$

BSEM/EDS

Archaeometallurgy

\begin{abstract}
A B S T R A C T
Energy dispersive X-ray fluorescence (EDXRF) is a well-known technique for non-destructive and in situ analysis of archaeological artifacts both in terms of the qualitative and quantitative elemental composition because of its rapidity and non-destructiveness. In this study EDXRF and realistic Monte Carlo simulation using the X-ray Monte Carlo (XRMC) code package have been combined to characterize a Cu-based bowl from the Iron Age burial from Fareleira 3 (Southern Portugal). The artifact displays a multilayered structure made up of three distinct layers: a) alloy substrate; b) green oxidized corrosion patina; and c) brownish carbonate soil-derived crust. To assess the reliability of Monte Carlo simulation in reproducing the composition of the bulk metal of the objects without recurring to potentially damaging patina's and crust's removal, portable EDXRF analysis was performed on cleaned and patina/crust coated areas of the artifact. Patina has been characterized by micro X-ray Diffractometry ( $\mu$ XRD) and Back-Scattered Scanning Electron Microscopy + Energy Dispersive Spectroscopy (BSEM + EDS). Results indicate that the EDXRF/Monte Carlo protocol is well suited when a two-layered model is considered, whereas in areas where the patina + crust surface coating is too thick, X-rays from the alloy substrate are not able to exit the sample.
\end{abstract}

(C) 2014 Elsevier B.V. All rights reserved.

\section{Introduction}

The quantitative characterization of the chemical composition of metal alloys in archaeological bronze artifacts by physical-chemical techniques is of utmost importance towards the identification of ancient production technologies, historical trade routes, raw material sources $(\mathrm{Cu}, \mathrm{Sn}, \mathrm{Pb})$ and more precise dating of the objects under investigation.

With the development of miniaturized X-ray detectors and tubes, allowing the production of hand-held portable spectrometers and insitu fast and affordable measurements, X-ray fluorescence spectroscopy has become a routine technique in the non-destructive analysis of archaeological alloys and metal art objects [1-5].

Once spectra have been obtained quantitative XRF analyses of the detected elements are a rather complex operation since many

\footnotetext{
Selected Paper from the Workshop on Monte Carlo Simulation Tools for X-ray Imaging and Fluorescence, ESRF, Grenoble, France, 24-25 February 2014.

* Corresponding author.

E-mail address: schiavon@uevora.pt (N. Schiavon).
}

parameters should be well known and kept under control. Moreover, a correct quantification requires an accurate estimative of background and/or a precise determination of the geometry of the experiment, taking into account also the roughness of the sample surface. Quantitative elaboration of the spectra is usually done with reference standards. However, algorithms able to describe the phenomena using measured parameters can also been used [6-8].

In this paper, we apply X-ray Monte Carlo (XRMC) codes [8] for the quantification of spectra acquired on a proto-historic bronze from southern Portugal. These are probabilistic simulation algorithms used in a number of research areas to solve high dimensional problems that cannot be accomplished in an analytical way.

In the case of X-ray interactions with matter, Monte Carlo simulations generate random (both in energy and direction) photons. Usually the majority of these photons do not reach the detector and so a large number of photons must be generated. In fact, a long time of simulation is required and a good statistic spectrum can last up to days before to be generated. However, there are some techniques called variance reduction techniques, which speed up the simulation forcing the detection of each generated photons [8]. 
For this purpose, two fast Monte Carlo codes have been developed for this kind of application in order to simulate a good quality spectrum in a couple of minutes, the same order of time required by the measurements [8-12]. Both of them are based on a constantly updated X-ray database, called Xraylib [13,14].

One of the main limits in obtaining reliable analyses of archaeological bronze alloy composition is the roughness of the surface $[8,15,16]$ together with the almost ubiquitous development of oxidized corrosion patinas with variable thickness usually composed by Cu-based oxides [17]. Moreover, on top of these patinas, a layer of encrusted mineral material from the soil where the object had been buried is often present. The application of Monte Carlo simulations can represent a useful analytical tool to overcome all of these constraints.

In fact, if the patina and the soil-derived crust are not previously removed, chemical analysis of the object usually reflects the composition of these components and not that of the original alloy. Cleaning and removal of both patina and soil layer before is therefore a necessary, albeit unwanted, practice in order to obtain the composition of the bulk of the metal.

The key idea of this paper is to construct a model of the experiment as well as one of the sample multilayered structure and then run iteratively the Monte Carlo until the simulated spectrum is an almost perfect reproduction of the measured spectrum. When this is obtained the sample is perfectly determined both in chemical composition and structure.

The advantage of this method is not only that the background is not removed (and so one of the main sources of error is removed) but also that structural information of the bronze object surface (i.e. thickness of corrosion/encrusted layers) may also be modeled considering the artifact as having a multilayered structure [18].

To test the feasibility of the application of a combined Monte Carlo simulation/X-ray Spectrometry approach in archaeometry research, in this study we have combined portable EDXRF with Realistic Monte Carlo simulations using the fast X-ray interaction XRMC software package to investigate a unique archaeological bronze object displaying a well formed corrosion patina and soil derived surface crust.

\section{Materials and methods}

\subsection{The bowl}

The bowl analyzed in this paper was part of a grave goods discovered in an Iron Age burial (Fig. 1) recently excavated in the site of Fareleira 3 (Beja, Southern Portugal). In the sepulture, an adult male skeleton was inhumed in fetal position and lateral decubitus, with the head facing west and the feet in the opposing direction. The grave goods consist of both metal artifacts and pottery: with regard to the first, beyond the bowl, two iron spearheads, a bi-metallic (iron and bronze) knife, a fibulae and other undefined artifacts were recovered. Pottery was constituted by three wheel-made cups placed at the feet of the dead.

The bowl is the most interesting object of the grave goods, both for the rarity with which this typology appears in the south of Portugal and for its state of conservation, being the only complete specimen from this region.

From a morphological point of view, it is a large $(\varnothing \mathrm{cm} 32)$ undecorated and hemispherical beaten Cu-based object, with opposed handles fixed with three rivets at the body of the recipient. One of the handles is lost. The bowl from Fareleira shows very interesting parallels with similar objects from eastern Mediterranean [19]. Based on typological features alone, it may be attributed to the Orientalizing Period, namely to the VII century BC [20].

\subsection{EDXRF and Monte Carlo simulation}

The XRF experiments performed here are based on the portable XRF system, composed by an Amptek MiniX X-ray tube equipped with Ag anode, $50 \mathrm{kV}$ max, $200 \mu \mathrm{A}$ max. The X-ray detector was an X-123 SDD by Amptek, coupled to a DSP Multichannel Analyzer, with a resolution

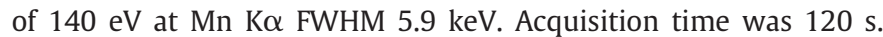
The detector was placed orthogonally to the sample surface while the X-ray tube was at $30^{\circ}$. Certificated bronze sample was used for the calibration. All measurements were carried out under ambient air.

Monte Carlo simulation codes used in the present study are fully described in Ref. [8].

Margin of error to be considered for the chemical composition are: $<2.00 \mathrm{wt}$.\% for the major elements ( $>5.030 \mathrm{wt} . \%$ ); $<5.00 \mathrm{wt} . \%$ for the elements between 1.00 and 5.00 wt.\%; $<10.00$ wt.\% between 0.50 and 1.0 wt.\%; and $<50 \%$ between 0.10 and 0.50 wt.\%.

\section{3. $\mu X R D$ and BSEM-EDS}

In order to characterize the patina, $\mu \mathrm{XRD}$ and BSEM-EDS have been utilized as auxiliary analytical methods. For $\mu \mathrm{XRD}$, a commercial BRUKER D8 Discover System with the DAVINCI design with a $\mathrm{Cu} \mathrm{K \alpha}$ source operating at $40 \mathrm{kV}$ and $40 \mathrm{~mA}$ and a LINXEYE ${ }^{\mathrm{TM}}$ 1-dimensional detector was used. The sample scraped from the oxidized corrosion patina of the bowl was deposited onto a flat zero-background sample holder and irradiated through a $0.6 \mathrm{~mm}$ slit. The micro beam was achieved using a Göbel mirror and a $1 \mathrm{~mm}$ collimator.

The angular range $(2 \theta)$ was scanned from $3^{\circ}$ to $70^{\circ}$ at a step size of $0.02^{\circ}$ with a counting time of $1 \mathrm{~s} / \mathrm{step}$. Evaluation of X-ray diffractograms was made by using the routines of the Diffrac. EVA
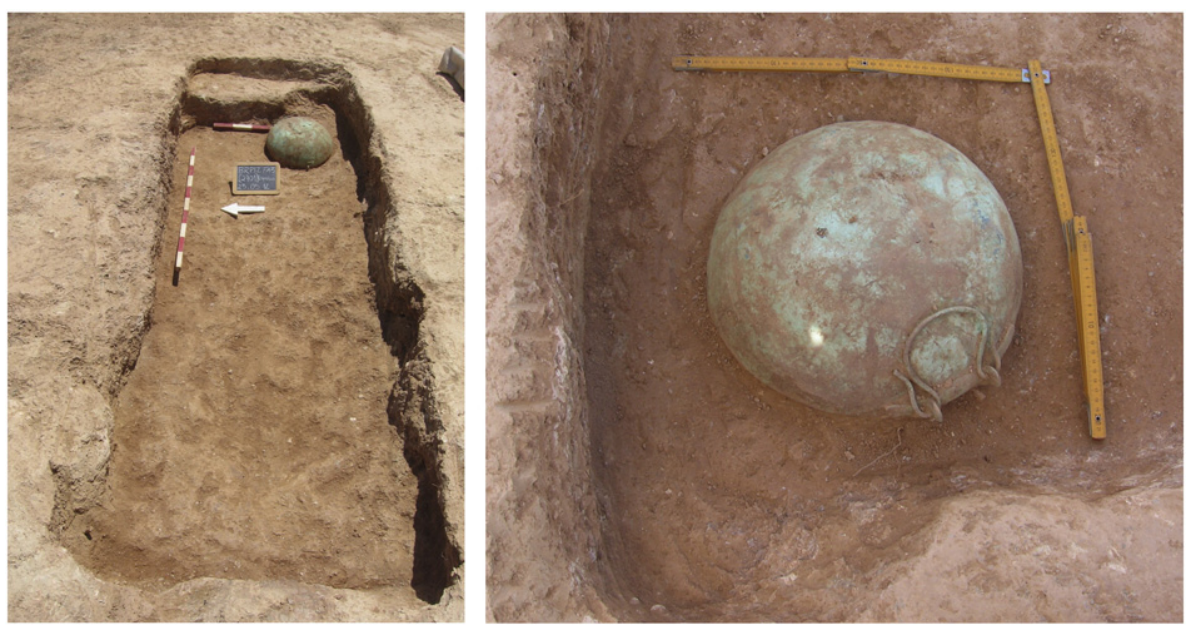

Fig. 1. Archaeological burial site with bronze bowl in its original position. 
software package (BRUKER/AXS GmbH, Germany) and the PDF-2 database files (ICDD, Denver, USA).

SEM-EDS was a HITACHI S3700N interfaced with a QUANTAX EDS microanalysis system. The QUANTAX system was equipped with a BRUKER AXS 5010XFlash ${ }^{\circledR}$ Silicon Drift Detector (129 eV Spectral Resolution at FWHM/Mn K $\alpha$ ). Standardless PB/ZAF quantitative elemental analysis was performed using the Bruker ESPRIT software. The operating conditions for EDS analysis were as follows: backscattered electron mode (BSEM), $20 \mathrm{kV}$ accelerating voltage, $10 \mathrm{~mm}$ working distance and $120 \mu \mathrm{A}$ emission current. The detection limits with this configuration for major elements (> Na) were in the order of $0.1 \mathrm{wt} . \%$.

\section{Results and discussion}

Four points of the sample analyzed here are discussed, corresponding to three different surface states or composition: a greenish (copper oxide), a brownish soil-derived crust, both from metal plate of the handle and two cleaned points.

In Fig. 2A, the spectrum from a cleaned surface, corresponding to the body of the bowl, is depicted superimposed to the Monte Carlo fit. The composition of the bulk metal is $97.00 \mathrm{wt} . \% \mathrm{Cu}$ and $1.30 \mathrm{wt} . \% \mathrm{Sn}$; $\mathrm{Fe}, \mathrm{Pb}, \mathrm{Ag}$ and $\mathrm{Ti}$ also occur, but as minor impurities ( $<0.50 \mathrm{wt} . \%)$.

The peak of the second cleaned metal surface is depicted in Fig. 2B. It corresponds to the plaque of the handle. In relation to the first analyzed point, this suggests a different chemical composition: $93.80 \mathrm{wt} . \%$ $\mathrm{Cu}, 1.50 \mathrm{wt} . \% \mathrm{Sn}$ and $4.15 \mathrm{wt} . \% \mathrm{~Pb}$. Other minor peaks are present as impurities, in a total amount less than $0.50 \mathrm{wt} . \%$. The handle of the bowl had therefore been manufactured with a leaded copper alloy. The concentration of $\mathrm{Pb}$ suggests that its presence may not be considered as accidental, but as the result of an intentional addition, most likely to lower the melting temperature and to increase the fluidity of the molten metal. Because $\mathrm{Pb}$ has substantially no solid solubility in $\mathrm{Cu}$ and $\mathrm{Cu}$-based alloys, if the percentage of lead in bronze is higher than a few percent, the number of lead globules increases as the percentage of $\mathrm{Pb}$ amount increases. The distribution and size of the $\mathrm{Pb}$ globules from the external surface to the core of the bronze artifact are strongly affected by the cooling process of the alloy. In fact, Pb-rich grains can be readily detected by BSEM-EDS within the microstructure of the bowl's alloy (Fig. 3). EDS mapping of the patina confirms a $\mathrm{Cu}-$ $\mathrm{Pb}-\mathrm{Sn}$-Fe composition (Fig. 4).

In Fig. $2 \mathrm{C}$ the spectrum of a point from a green surfaced area is displayed. In this case, a $100 \mu \mathrm{m}$ thick oxide patina is found. The oxidation patina is formed by copper, lead and tin. The composition of the metal substrate is identical to the one present in the cleaned sample.

$\mu \mathrm{XRD}$ analysis of the patina identified the presence as crystalline phases of typical bronze corrosion products [17]: Cuprite $\left(\mathrm{Cu}_{2} \mathrm{O}\right)$, Malachite $\left.\mathrm{Cu}_{2}\left(\mathrm{CO}_{3}\right)(\mathrm{OH})_{2}\right)$ and Paratacamite $\left(\mathrm{Cu}_{3}(\mathrm{Cu}, \mathrm{Zn})(\mathrm{OH})_{6} \mathrm{Cl}_{2}\right)$. The Quartz peaks present may be considered as a contamination from adjacent soil derived crust.

In Fig. 2D, the X-ray spectrum from the brownish crust superimposed to the simulation is displayed. A carbonate layer superimposed to an oxide layer and finally to the bronze layer has been identified. The
A

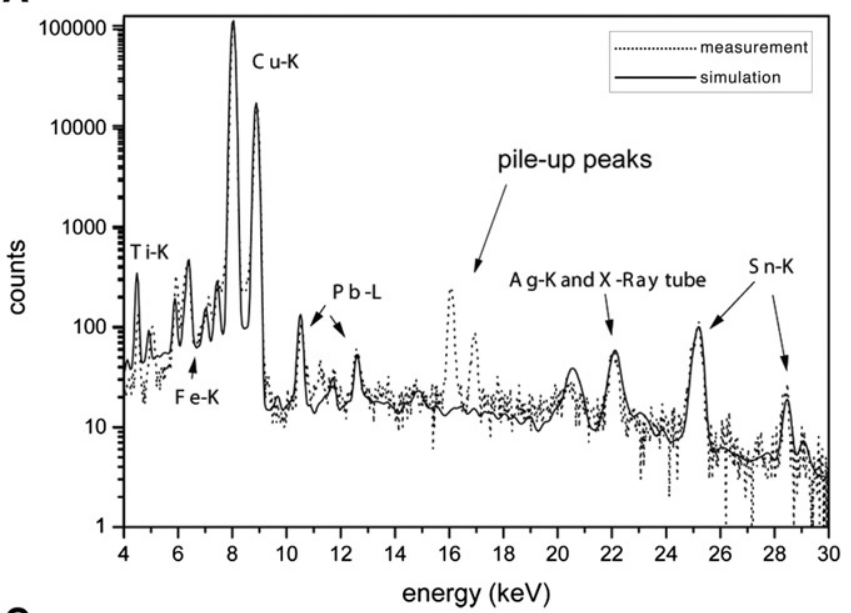

C

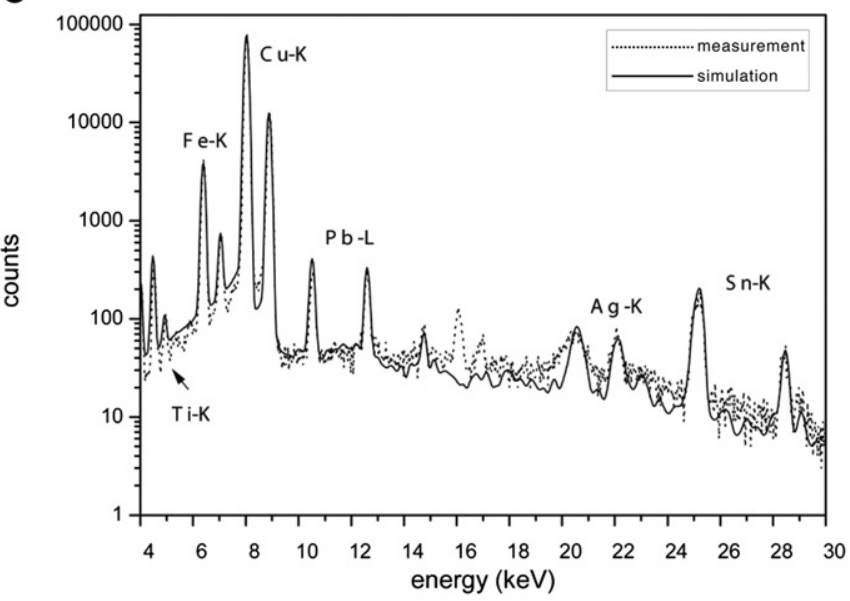

B

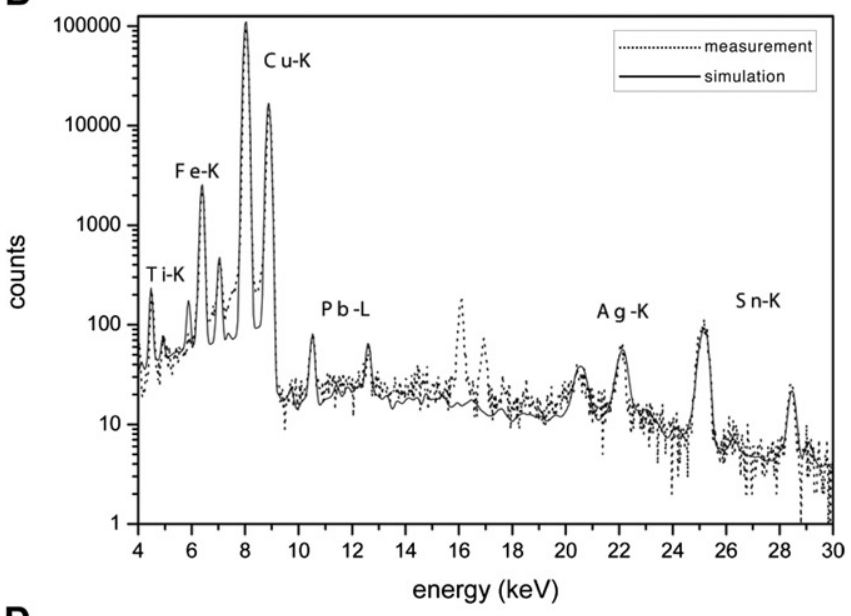

D

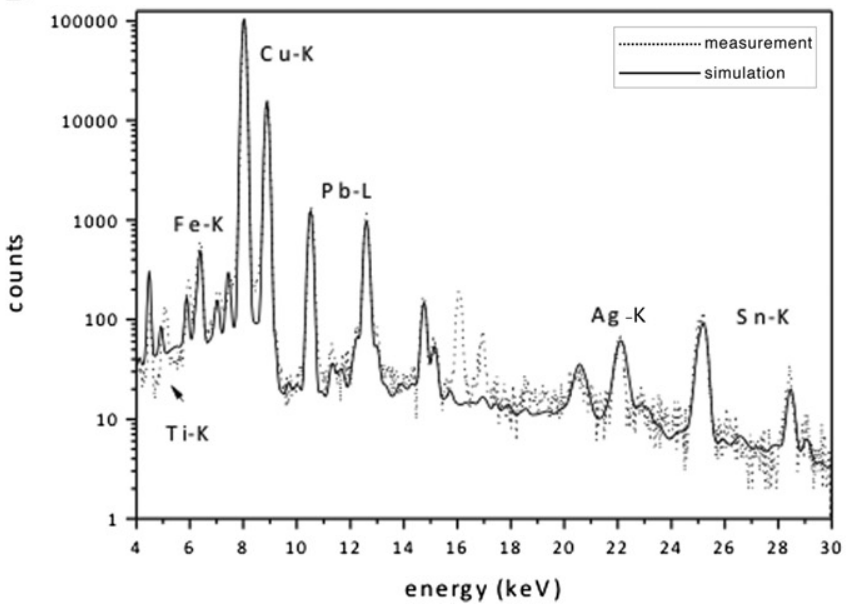

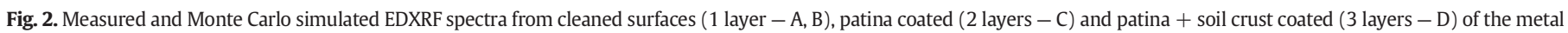
alloy. 

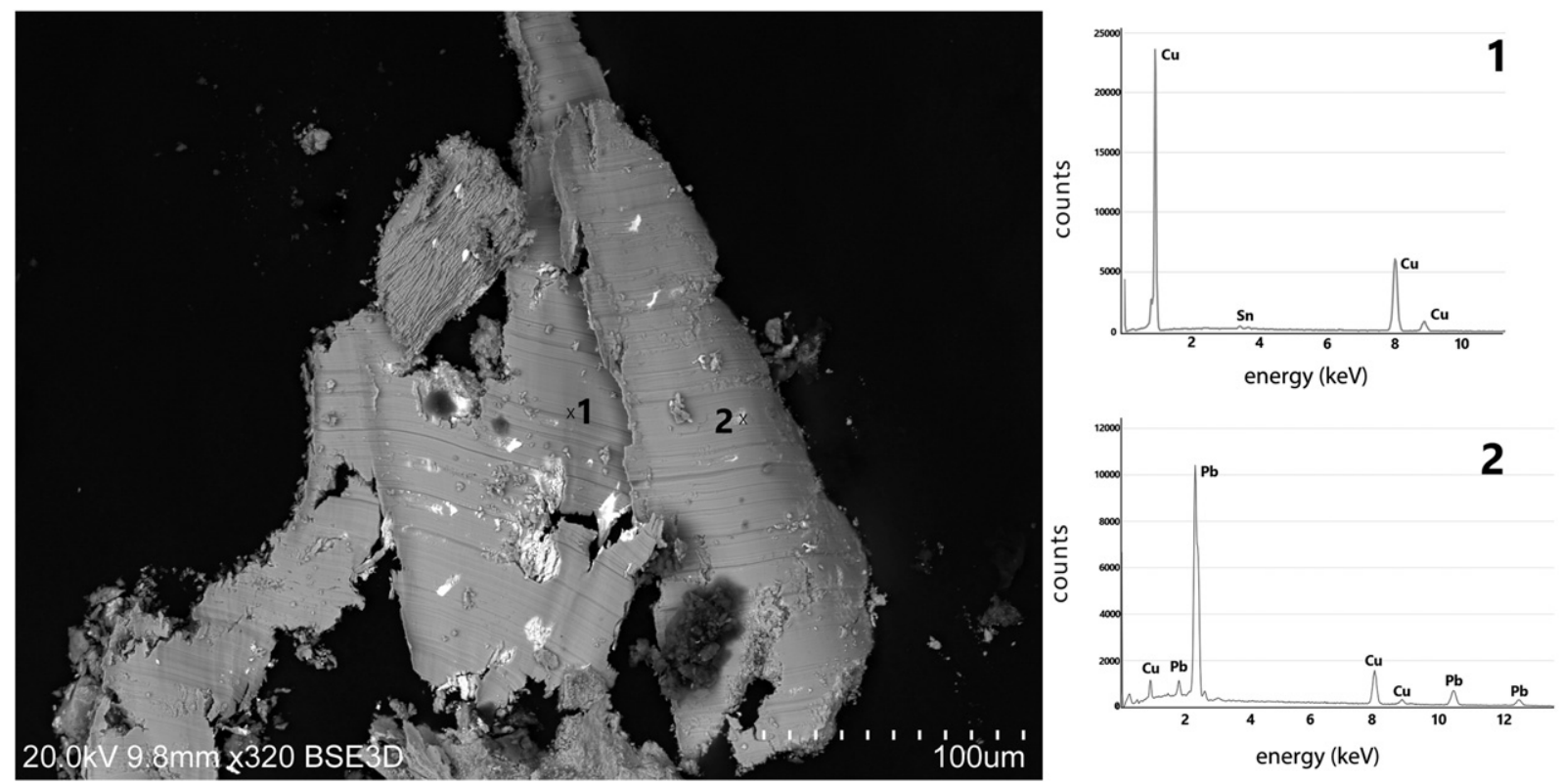

Fig. 3. BSEM + EDS spectra of a fragment of bowl's alloy showing development of Pb-enriched regions (bright areas) within the alloy's structure.

carbonate layer is $60 \mu \mathrm{m}$ thick while the oxide one is $50 \mu \mathrm{m}$ thick. The oxidized layer is composed of oxide of copper with a small amount of iron and lead (both around $1.00 \mathrm{wt} . \%$ ). The bronze layer is composed of $56.00 \mathrm{wt} . \% \mathrm{Cu}$ and $3.00 \mathrm{wt} . \% \mathrm{Sn}$. The low concentration of $\mathrm{Cu}$, as opposed to the one normally found in bronze alloys, is an indicator that also the third layer is oxidized and so the overall thickness of these three layers is too thick to allow the X-rays to exit from the sample.

The data obtained with the Monte Carlo simulation of X-ray fluorescence spectra, both from the two cleaned areas and the green-like (copper oxide) layer, point out that the chemical composition of the bowl from Fareleira 3 agrees with the Iron Age metallurgy from the SW parts of the Iberian Peninsula. The bowl is a Cu-based artifact with variable amounts of $\mathrm{Pb}$, mainly concentrated in the handle. The noteworthy presence of $\mathrm{Pb}$ in the objects under study is also compatible with other coeval metals: the analyses of a group of artifacts from Quinta do Almaraz, for instance, have recently revealed a significant usage of leaded bronzes (up to $5.90 \pm 0.20 \mathrm{wt} . \% \mathrm{~Pb}$ ) since the Iron Age Orientalizing period [21].
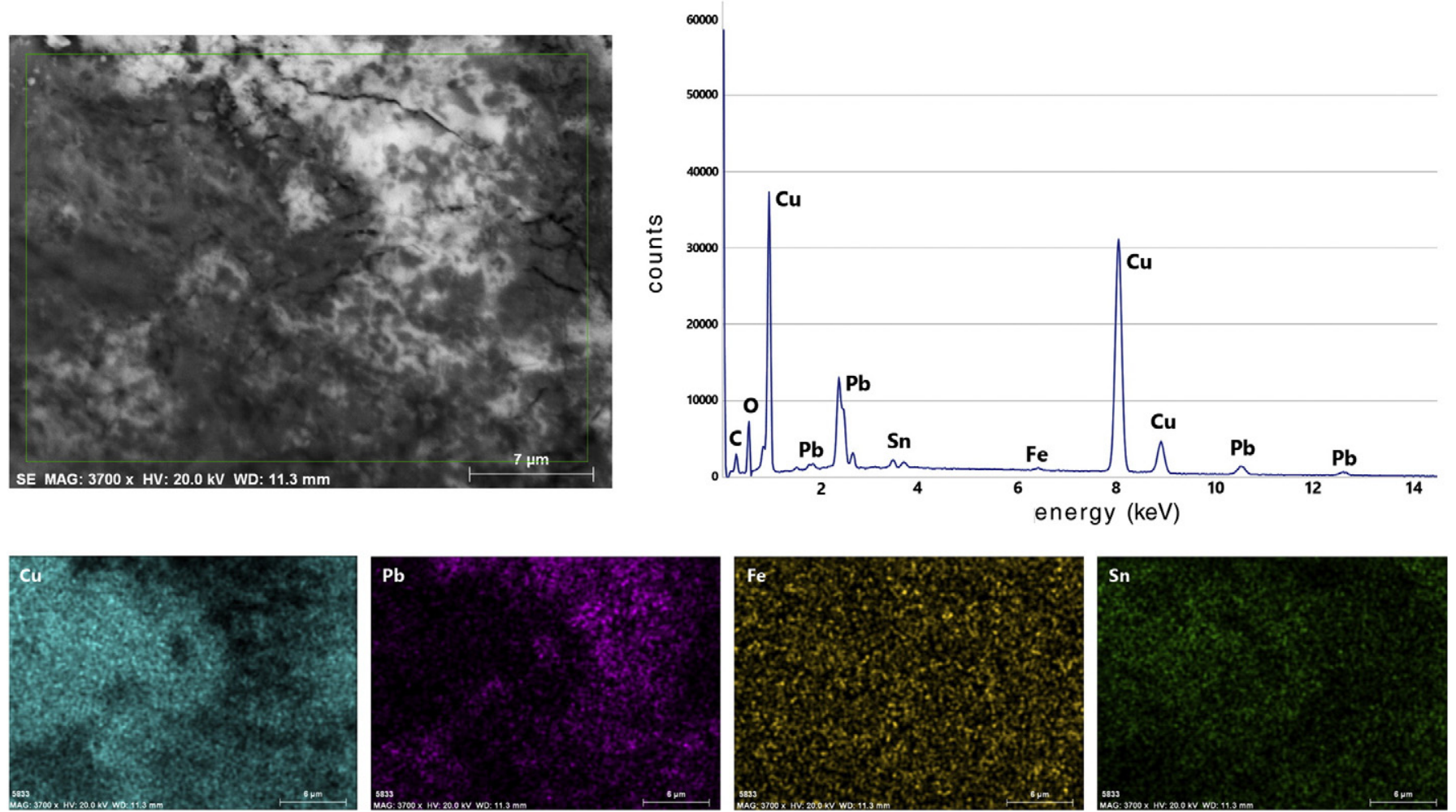

Fig. 4. EDS mapping of the corrosion patina's surface showing a $\mathrm{Cu}-\mathrm{Pb}-\mathrm{Sn}-\mathrm{Fe}$ composition. $\mathrm{Pb}$ oxides are probably amorphous. 
The analyzed points also present remarkable low Sn contents, suggesting a probable use of recycling of bronze scrap as raw material or the occurrence of $\mathrm{Sn}$ in the polymetallic Cu-ores used for the manufacturing of the artifact [22]. This situation is in line with other Cu-based artifacts from the Early Iron Age from southern Portugal [3, $22,23]$.

\section{Conclusions}

For an archaeologist, the possibility of analyzing in a fast reliable manner the alloy of the bronze object directly at the excavation sites without the need for removing both corrosion patinas and encrusted layers would represent an important step forward.

In this paper, Monte Carlo simulation has been tested on an Iron Age bowl from southern Portugal. This object has a multilayered structure made up of the sequence of superimposed layers with different compositions: the bulk metal, the green oxidized corrosion patina and the soil crust.

The combined analytical protocol of EDXRF with Realistic Monte Carlo simulation using the fast XRMC code used in this study has proved itself to be well suited in the case of a two layered model whereas in three layered areas (alloy-patina-crust) where the surface coating is too thick, X-rays from the alloy substrate were not able to exit the sample. As a matter of fact, the method appears to be very sensible to small changes in layer thickness and composition. This is essentially due to the changes of relative fluorescence peak ratios due to the layer attenuation, which depends on the position of a specific element in the multilayer structure and/or on the changes of the background due to the scatterings. Of course, if a chemical element is present as a major element in a layer and in traces in another one, Monte Carlo or other methods are not suitable, because the contribution of the trace element on the total peak area is negligible with respect to the statistical noise. In any case, the approach presented may be particularly useful in cases, like the one tested in this paper, when a large number of bronze artifacts recovered from an archaeological sites need to be analyzed without the need for cumbersome and potentially damaging cleaning and patina removal.

In summary, results indicate that the EDXRF/Monte Carlo protocol may represent a reliable tool to obtain a rapid, in-situ and nondestructive approximation of the composition of an archaeological artifact even in the case of alloys displaying a non-homogeneous chemical composition.

\section{Acknowledgments}

Carlo Bottaini acknowledges the INALENTEJO program for PostDoctoral research grant within IMAGOS project (ALENT-07-0224FEDER-0017461 and ALENT-027-0224-FEDER-001760). We thank the editor and two anonymous referees for their comments that greatly improved the original manuscript.

\section{References}

[1] M.F. Guerra, Analysis of archaeological metals. The place of XRF and PIXE in the determination of technology and provenance, X-Ray Spectrom. 27 (1998) 73-80 (doi:10.1002/(SICI)1097-4539(199803/04)27:2<73::AID-XRS249>3.0.CO;2-5).

[2] E. Figueiredo, M.F. Araujo, R.J. Silva, R. Vilar, Characterisation of a proto-historic bronze collection by micro-EDXRF, Nucl. Inst. Methods Phys. Res. Sect. B Beam Interact. Mater. Atoms 296 (2013) 26-31, http://dx.doi.org/10.1016/j.nimb.2012.11.019.
3] N. Schiavon, A. Celauro, M. Manso, A. Brunetti, F. Susanna, Iron-age bronze statuettes in southern Portugal: combining archaeological data with EDXRF and BSEM + EDS to assess provenance and production technology, Appl. Phys. A 113 (2013) 865-875, http://dx.doi.org/10.1007/s00339-013-7747-7.

[4] A. Celauro, N. Schiavon, A. Brunetti, L. Manfredi, F. Susanna, A. Dekayir, V. Graziani, D. Pargny, D. Ferro, Combining chemical data with GIS and PCA to investigate Phoenician-Punic Cu-metallurgy, Appl. Phys. 114 (2014) 711-722, http://dx.doi. org/10.1007/s00339-013-8179-0.

[5] A.M. Cardeira, R.B. Camara, P. Strzelec, N. Schiavon, J. Mirão, A. Candeias, M.L. Carvalho, M. Manso, White spots on Smoke Rings by Bruce Nauman: a case study on contemporary art conservation using microanalytical techniques, Microscopy and Microanalysis, 2014., http://dx.doi.org/10.1017/S1431927614013002 (Published online).

[6] M. Mantler, H. Ebel, X-ray fluorescence analysis without standards, X-Ray Spectrom. 9 (1980) 146-149, http://dx.doi.org/10.1002/xrs.1300090312.

[7] T. Kovács, M. Kis-Varga, Application of an empirical correction method for the x-ray fluorescence analysis of copper alloys, X-Ray Spectrom. 15 (1986) 221-225, http:// dx.doi.org/10.1002/xrs.1300150313.

[8] A. Brunetti, B. Golosio, A new Monte Carlo code for simulation of the effect of irregular surfaces on X-ray spectra, Spectrochim. Acta Part B 94-95 (2014) 58-62, http://dx.doi.org/10.1016/j.sab.2014.03.007.

[9] L. Vincze, K. Janssens, F. Adams, A general Monte Carlo simulation of energydispersive X-ray fluorescence spectrometers - I. Unpolarized radiation, homogeneous samples, Spectrochim. Acta Part B 48 (1993) 553-573, http://dx.doi.org/10. 1016/0584-8547(93)80060-8.

[10] T. Schoonjans, L. Vincze, V.A. Solé, M. Sanchez del Rio, P. Brondeel, G. Silversmit, K. Appel, C. Ferrero, A general Monte Carlo simulation of energy-dispersive X-ray fluorescence spectrometers - part 5. Polarized radiation, stratified samples, cascade effects, M-lines, Spectrochim. Acta Part B 70 (2012) 10-23, http://dx.doi.org/10. 1016/j.sab.2012.03.011.

[11] U. Bottigli, A. Brunetti, B. Golosio, P. Oliva, S. Stumbo, L. Vincze, P. Randaccio, P. Bleuet, A. Simionovici, A. Somogyi, Voxel-based Monte Carlo simulation of X-ray imaging and spectroscopy experiments, Spectrochim. Acta B At. Spectrosc. 59 (2004) 1747-1754, http://dx.doi.org/10.1016/j.sab.2004.03.016.

[12] B. Golosio, A. Brunetti, G.L. Masala, P. Oliva, T. Schoonjans, Monte Carlo simulation of $\mathrm{X}$-ray imaging and spectroscopy experiments using quadric geometry and variance reduction techniques, Comput. Phys. Commun. 185 (2014) 1044-1052, http://dx. doi.org/10.1016/j.cpc.2013.10.034

[13] A. Brunetti, M. Sanchez del Rio, B. Golosio, A. Simionovici, A. Somogyi, A library for X-ray-matter interaction cross sections for X-ray fluorescence applications, Spectrochim. Acta Part B 59 (2004) 1725-1731, http://dx.doi.org/10.1016/j.sab. 2004.03.014.

[14] T. Schoonjans, A. Brunetti, B. Golosio, M. Sanchez del Rio, V.A. Solé, C. Ferrero, L. Vincze, The Xraylib library for X-ray-matter interactions. Recent developments, Spectrochim. Acta Part B 66 (2011) 776-784, http://dx.doi.org/10.1016/j.sab.2011.09.011.

[15] L. Bonizzoni, A. Maloni, M. Milazzo, Evaluation of effects of irregular shape on quantitative XRF analysis of metal objects, X-Ray Spectrom. 35 (2006) 390-399, http://dx.doi.org/10.1002/xrs.926.

[16] T. Trojek, Reconstruction of the relief of an investigated object with scanning X-ray fluorescence microanalysis and Monte Carlo simulations of surface effects, Appl. Radiat. Isot. 70 (2012) 1206-1209, http://dx.doi.org/10.1016/j.apradiso.2011.11.012.

[17] K.P. Fitzgerald, J. Nairn, A. Atrens, The chemistry of copper patination, Corros. Sci. 39 (1998) 2029-2050, http://dx.doi.org/10.1016/S0010-938X(98)00093-6.

[18] R.T. de Cesareo, J. Assis, C. Roldán, C. Bustamante, A. Brunetti, N. Schiavon, Multilayered samples reconstructed by measuring $\mathrm{Ka} / \mathrm{K} ß$ or La/Lß X-ray intensity ratios by EDXRF, Nucl. Inst. Methods Phys. Res. Sect. B 312 (2013) 15-22.

[19] H. Matthaus, Metallgefasse und Gefassuntersatze der Bronzezeit, der geometrischen und archaischen Periode auf Cypern: mit einem Anhang der bronzezeitlichen Schwertfunde auf Cypern, Prahistorische Bronzefunde, Abteilung II; Bd. 8, Munchen, 1985.

[20] F.J. Jiménez Avila, La toréutica orientalizante en la Península Ibérica, Real Academia de la Historia, Madrid, 2002.

[21] P. Valério, R. Silva, M. Arajo, A. Soares, L. Barros, A multianalytical approach to study the Phoenician bronze technology in the Iberian Peninsula - a view from Auinta do Almaraz, Mater. Charact. 67 (2012) 74-82, http://dx.doi.org/10.1016/j.matchar. 2012.02.020.

[22] R.F. Tylecote, The Prehistory of Metallurgy in the British Isles, Institute of Metals, London, 1986.

[23] P. Valério, A.M.M. Soares, M.F. Araújo, R.J.C. Silva, F.J.C. Santos, The distinctive grave goods from Palhais (Beja, Portugal). New insights into the metallurgical evolution under Orientalizing influence in the southwestern end of Iberia, Trab. Prehist. 70 (2013) 361-371, http://dx.doi.org/10.3989/tp.2013.12119. 